\title{
Elasticity changes anti-correlate with NO production for human endothelial cells stimulated with TNF- $\alpha$
}

\author{
Agnieszka M. Szczygiel • Grzegorz Brzezinka • \\ Marta Targosz-Korecka · Stefan Chlopicki · \\ Marek Szymonski
}

Received: 16 May 2011 / Revised: 4 October 2011 / Accepted: 17 October 2011 / Published online: 13 December 2011

(C) The Author(s) 2011. This article is published with open access at Springerlink.com

\begin{abstract}
Tumor necrosis factor alpha (TNF- $\alpha$ ) is a critical cytokine that is involved in systemic inflammatory response and contributes to the activation of the proinflammatory phenotype of the endothelium. In the present study, effects of TNF- $\alpha$ on morphology and elasticity of endothelium in relation to the production of NO and actin fiber reorganization were analyzed in human dermal microvascular endothelial cells. The cells were incubated in MCDB medium solution and stimulated with $10 \mathrm{ng} / \mathrm{ml}$ of TNF- $\alpha$. Atomic force microscopy measurements have enabled characterization of cell morphology and elastic properties in physiological conditions. The spectrophotometric Griess method was applied to estimate nitric oxide (NO) production of the cells. We demonstrated that TNF- $\alpha$-induced changes in elasticity of endothelium anti-correlate with NO production and are associated with the reorganization of actin cytoskeleton.
\end{abstract}

Keywords Endothelium - Tumor necrosis factor- $\alpha$. Nitric oxide - Atomic force microscopy $\cdot$ Cytoskeleton

\footnotetext{
A. M. Szczygiel · G. Brzezinka (凶) · M. Targosz-Korecka • M. Szymonski

Department of Physics of Nanostructures and Nanotechnology, Jagiellonian University, Reymonta 4, 30-059, Krakow, Poland e-mail: g.brzezinka@uj.edu.pl

S. Chlopicki

Department of Experimental Pharmacology, Chair of Pharmacology, Medical College and Jagiellonian Centre for Experimental Therapeutics (JCET),

Jagiellonian University, Krakow, Poland
}

\section{Introduction}

The endothelium is regarded as the biggest endocrine organ in human body [19]. It forms a tight monolayer of cells on the luminal side of blood vessels, and thus, it maintains a natural barrier between blood and other layers of blood vessels. Wide research on endothelium has uncovered a huge variety of its functions that contribute to the homeostasis of the cardiovascular system. Endothelium produces and reacts to numerous chemical compounds and regulates the vascular tone (i.e., relaxation and contraction of blood vessels) through paracrine response. Endotheliumderived mediators regulate not only blood flow but are also involved in angiogenesis and are fundamental in the regulation of vessels thromboresistance [10]. Endothelial activation is crucial in the inflammatory response initiating leukocyte engagement process, which recruits leukocytes to the site of inflammation [21].

Various cell signaling pathways (i.e., mechanotransduction processes) and cytoskeletal rearrangements are triggered by changes in the physical stress and forces applied to the cell. Endothelial cells, similarly to muscle or red blood cells, due to their function and location undergo constant squeezing and stretching from the environment. As a result, elasticity of endothelial cells plays a key role in the maintenance of proper blood vessel flow, vascular pressure regulation, and other endogenous functions. For this reason, the determination of cell mechanical properties may point out to its physiological functional state. On the other hand, nonphysiological values of elasticity may represent a sign of malfunction of endothelium that contribute to the variety of cardiovascular diseases [4]. 
In recent years, in addition to biochemical and physiological studies, research on mechanical properties of the endothelial cells has been performed. Among that, a great potential of atomic force microscopy (AFM) and spectroscopy techniques for determination of cell shape, membrane structure, its stiffness, and adhesive properties was demonstrated. Oberleithner et al. have found rapid response of the endothelial cells to mineralocorticoid hormone aldosterone manifesting in the changes of volume of the central (nuclear) cell compartment and its elasticity $[11,13]$. Later, the study on the influence of the plasma sodium and potassium concentration on endothelial cell stiffness has shown anticorrelation with nitric oxide release (NO is the strongest among known vasodilators) $[12,14]$. The response of endothelial cell lines derived from different parts of human body to the same chemical compound may vary, as shown in [13]. Indeed endothelial cells of bovine aorta were significantly swelling in presence of $0.1 \mathrm{nM}$ aldosterone, while the same effect was observed for substantially higher $(100 \mathrm{nM})$ concentration of the hormone for human umbilical vein endothelial cells (HUVEC).

The purpose of this work is to investigate the endothelial inflammatory response, which is crucial for systemic homeostasis. Tumor necrosis factor alpha $(\mathrm{TNF}-\alpha)$ is one of the human cytokines stimulating acute phase reaction and systemic inflammation. It is produced mainly by local inflammatory cells (macrophages and monocytes) but also by endothelial cells [19]. It is known that $12 \mathrm{~h}$ stimulation by $\mathrm{TNF}-\alpha(5 \mathrm{ng} / \mathrm{ml})$ has significantly increased the intercellular adhesion molecule 1 expression (4-fold) and leukocyte adhesion (20-fold) [3], which confirms the inflammatory state triggered by this molecule. Recent research performed by our group has revealed the response of EA.hy926 (permanent human umbilical vein endothelial cell line) to long-time exposure to TNF$\alpha$, which affects the cell shape and elasticity (unpublished results). Basing on the fact that TNF- $\alpha$ induces inflammation of endothelium and it is also produced by those cells, this cytokine was chosen by our group to investigate the properties of dysfunctional endothelium. The response of endothelial cells induced by the same amount of chemical or mechanical stimulation may significantly vary [13]; hence, in this work, the response of human dermal microvascular endothelial cells (HMEC) is determined in terms of morphology, stiffness, and nitric oxide production in exposition to TNF- $\alpha$. Furthermore, a hypothesis is proposed, which may explain observed changes by processes related to endothelial cytoskeleton reorganization. Additionally, fluorescent $\mathrm{F}$-actin staining experiment may confirm the hypothesis. Our research has revealed a similar behavior for EA.hy926 cell line, where the influence of TNF- $\alpha$ on nitric oxide production was determined in addition to previous research on this cell line.

\section{Experimental details}

\section{Materials}

The HMEC were received courtesy of Center for Disease Control and Prevention, Atlanta (GA, USA). Hybridoma EA.hy926 cell line, formed by the fusion of HUVEC with the human lung carcinoma cell line, A549 [7], was kindly provided by Dr C-J. Edgell (Department of Pathology University of North Carolina, Chapel Hill, NC, USA) [7]. Pol-L-lysine glass slides were obtained from Thermo Scientific. L-Glutamine, human epidermal growth factor (EGF), fetal bovine serum (FBS), and unit of antibiotics-penicillin, streptomycin, and fungison-were bought from Invitrogen (Warsaw, Poland). MCDB medium, Dulbecco's phosphate-buffered saline (D-PBS; pH 7.4) $1 \times$, trypsin $(0.25 \%)$, hydrocortisone, and TNF- $\alpha$ were purchased from Sigma Aldrich (Poznan, Poland). Fluorescent stains (Phallotoxine-Alexa Fluor 488 phalloidin and DAPI) was bought from Invitrogen (Warsaw, Poland). All the solvents were Lab (suitable for general laboratory applications) and A.C.S. (high-quality) grade. All the products have been used without additional purification.

\section{Cell culture}

For HMEC culturing, MCDB medium was used with a final serum concentration of $10 \%$, L-glutamine of $1 \%$, hydrocortisone of $2 \%$, EGF of $0.001 \%$, and antibiotics (penicillin, streptomycin, and fungison) of $0.1 \%$. The cells were seeded on the culture flasks after 3 days of incubation at $37^{\circ} \mathrm{C}$. After that, cells were rinsed with D-PBS (pH 7.4) and then incubated in $3 \mathrm{ml}$ of trypsin in order to detach the adherent cells from the flask. This process was continued at $37^{\circ} \mathrm{C}$ until $90 \%$ of cells were collected. The trypsin was then neutralized by adding $2 \mathrm{ml}$ of serum and $5 \mathrm{ml}$ of MCDB medium to the flask, and the prepared solution was thereafter transferred to a $15-\mathrm{ml}$ sterile centrifuge tube. The cells were centrifuged at 1,200 for $5 \mathrm{~min}$ and re-suspended in fresh growth medium.

EA.hy 926 is a permanent cell line derived by fusing human umbilical vein endothelial cells with cell line A549. Cells were grown in DMEM supplemented with $10 \%$ fetal bovine serum, $2 \mathrm{mM}$ L-glutamine, $100 \mathrm{IU}$ penicillin, $100 \mu \mathrm{g}$ streptomycin, and $2 \%$ HAT Supplement (GIBCO). Cultures were maintained at $37^{\circ} \mathrm{C}$ in 
a fully humidified atmosphere of $5 \% \mathrm{CO}_{2}$ in air. Cells were passaged twice a week.

\section{Preparation of the samples}

Pol-L-lysine glass was cleaved into $1 \times 1 \mathrm{~cm}$ plates. Next, the surfaces were rinsed with ethanol and sterilized with UV light in laminar chamber for $30 \mathrm{~min}$. After cleaning, the samples were exposed to human dermal microvascular endothelial cells from third or fourth passage at a concentration of $4 \times 10^{4}$ cells $/ \mathrm{ml}$ for $48 \mathrm{~h}$. This process was continued at $37^{\circ} \mathrm{C}$ and atmosphere with $5 \%$ of $\mathrm{CO}_{2}$ concentration. Then, samples with cells were exposed to TNF- $\alpha$ for various incubation periods $(1,3,6,12$, and $24 \mathrm{~h})$. For each incubation period, a cytokine unexposed sample was prepared in parallel as a reference. TNF- $\alpha$ was dissolved in fresh medium in concentration of $10 \mathrm{ng} / \mathrm{ml}$. Loosely bound cells were removed from the surface by rinsing the substrate with fresh medium heated to $37^{\circ} \mathrm{C}$.

Petrache et. al have shown that $100 \mathrm{ng} / \mathrm{ml}$ of TNF$\alpha$ leads to increased apoptosis of endothelial cells [15]. Thus, for the presented research, an order of magnitude lower concentration of TNF- $\alpha(10 \mathrm{ng} / \mathrm{ml})$ was used. Fluorescent apoptosis control tests have not revealed any increased apoptosis for this concentration up to $48 \mathrm{~h}$ of incubation. Cells were fixed using $2.5 \%$ glutaraldehyde for morphology measurements in order to reduce the elastic deformation during imaging [22].

\section{Fluorescence}

In order to visualize the cytoskeleton reorganization induced by $\mathrm{TNF}-\alpha$, F-actin fibers and nucleic acids were stained with Alexa Fluor 488 and DAPI, respectively. Prior to staining, cells were rinsed with warm phosphate-buffered saline solution. Then cells were fixed with $2 \%$ formaldehyde for $10 \mathrm{~min}$ and permeabilized $0.1 \%$ Triton $\mathrm{X}$ for $4 \mathrm{~min}$. Next, cells were incubated with PBS and 1\% BSA and then stained with Phallodoxine $(10 / 500 \mu \mathrm{l}$ PBS) for $16 \mathrm{~min}$ in room temperature. In the end, DAPI in the final concentration of $0.00025 \%(w / v)$ was added for $4 \mathrm{~min}$. Each of the described steps was followed by double rinsing with PBS. The cells were excited with Olympus X-Cite Q120 lamp, observed by Olympus U-MWU2 (DAPI) and UMWIB2 (Phallodoxine) filters, and visualized through Olympus IX71 with $\times 20$ objective. The images were recorded and then processed with Olympus CellSense software.

\section{Atomic force spectroscopy}

Elasticity measurements Atomic force spectroscopy is one of the most versatile techniques allowing the de- termination of mechanical properties in the nanometer scale. Morphology and elasticity were measured using Nanoscope IIIa Multimode-SPM (Veeco Instruments, Santa Barbara, CA, USA) with soft triangular cantilevers (MLCT multilever, spring constant around $0.01 \mathrm{~N} / \mathrm{m}$, Veeco Probes, Camarillo, CA, USA). Tip radius and geometry were determined by scanning TGT1 (NT-MDT) spike grid standard in contact mode and deconvoluted in SPIP software. The spring constant of all used cantilevers was calculated from the thermal oscillations of unloaded lever in air [16] and analyzed by NanoScope 6.1 software. Prior to measurements, deflection sensitivity and calibration curve were determined on a bare glass immersed in medium. Samples were placed on the piezo scanner and measured without fixation inside liquid cell in medium pre-warmed to $37^{\circ} \mathrm{C}$. First, topography of the surface was recorded in AFM contact mode. Then, a region of average size of $7 \times 7 \mu \mathrm{m}$ was selected in the central part of the cell, where 144 force-distance curves were collected on the rectangular grid of points. For each sample, at least eight different cells were characterized.

Model Assuming several simplifying conditions, cell indentation with AFM probe may be considered as the elastic deformation of a flat, soft sample under a stiff probe of conical or spherical shape, which is described by the Sneddon's modification of the Hertz model introduced elsewhere $[9,17]$. Although in case of living cells assumptions of this model are not met completely, it is useful to determine a quantitative elasticity parameter $E$, which is often regarded as an equivalent of Hooke's law Young's modulus. In case of this study, the paraboloidal model is employed, since it offers a better fit to the acquired force-indentation curves. According to the model, the dependence between the force $F$ exerted by the tip and indentation depth $\delta$ may be expressed by the following power function:

$F(\delta)=\frac{4}{3} \frac{E}{1-v^{2}} \sqrt{R} \delta^{3 / 2}$,

where $R$ is the tip radius and Poisson ratio $v$ is assumed to be 0.5 (isotropic elastic properties for small deformations).

Optimal force determination Prior to experiments, the dependence between applied loading force and elasticity parameter $E$ was determined. For this purpose, the force exerted by the tip was changed within a range of 0.4 to $4 \mathrm{nN}$, and respective force-indentation curves were collected on the control cells. Data analysis has shown the initial increase of the elasticity parameter with the plateau afterward (Fig. 1). Basing on the latter, for further measurements, the force equal to $1.5 \mathrm{nN}$ was 


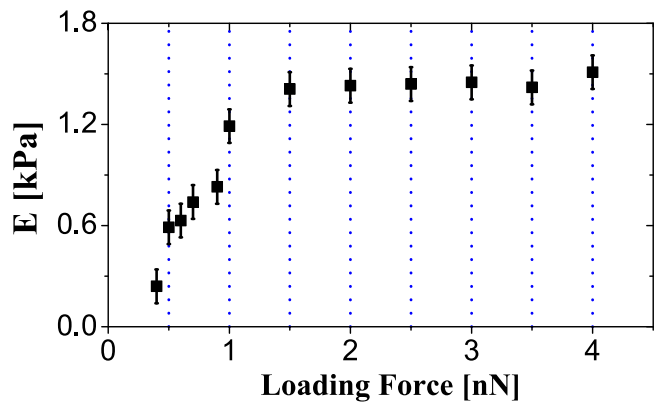

Fig. 1 Relation between loading force applied to the cell and calculated elasticity parameter $E$. After the initial increase, the elasticity value stabilizes for forces higher than $1.5 \mathrm{nN}$

chosen, as it is the plateau limit and thus the smallest value giving repetitive and comparable results.

Data analysis Elasticity parameter was calculated for every force-indentation curve applying the model. Results plotted in Fig. 2 are in the form of cumulative histograms: each histogram is based on all cells analyzed for a given sample. The positive skewness is revealed, which may be explained as a response from base glass obtained during indentation of thin, marginal part of the cell. Descriptive statistical tests performed in Statistica 9.0 (StatSoft Inc., Tulsa, OK, USA) have confirmed log-normal data distribution with significance level 0.05
(Shapiro-Wilk and Kolmogorov-Smirnov methods). Further on, elasticity parameter E quoted in the text corresponds to the median of log-normal distribution fits.

\section{Nitric oxide determination}

Endothelium actively participates and is an important effector organ in systemic inflammatory response. Under the influence of inflammatory agent, endothelial functions reorganize in order to increase inflammatory mediators secretion and the activity of adhesion molecules. Pro-inflammatory response of endothelium is closely associated with changes in the production of vasoprotective mediators, e.g., nitric oxide (NO). The latter is an unstable molecule, which is quickly metabolized to more stable nitrite $\mathrm{NO}_{2}^{-}$and nitrate $\mathrm{NO}_{3}^{-}$. The initial concentration of NO may be indirectly measured by nitrite and nitrate determination [6]. Briefly, $100 \mu \mathrm{l}$ of solution was obtained from supernatants of the HMEC culture and incubated with an equal volume of Griess reagent ( $0.35 \%$ 4-4-aminophenyl sulfone, $0.1 \% \mathrm{~N}$-(1-naphthyl) ethylenediamine dihydrochloride in $1 \mathrm{M} \mathrm{HCl}$ ) at room temperature for $10 \mathrm{~min}$. The absorbance at $550 \mathrm{~nm}$ was measured and nitrite concentration was calculated from a sodium nitrite standard curve [1]. The percentage changes of the nitric oxide
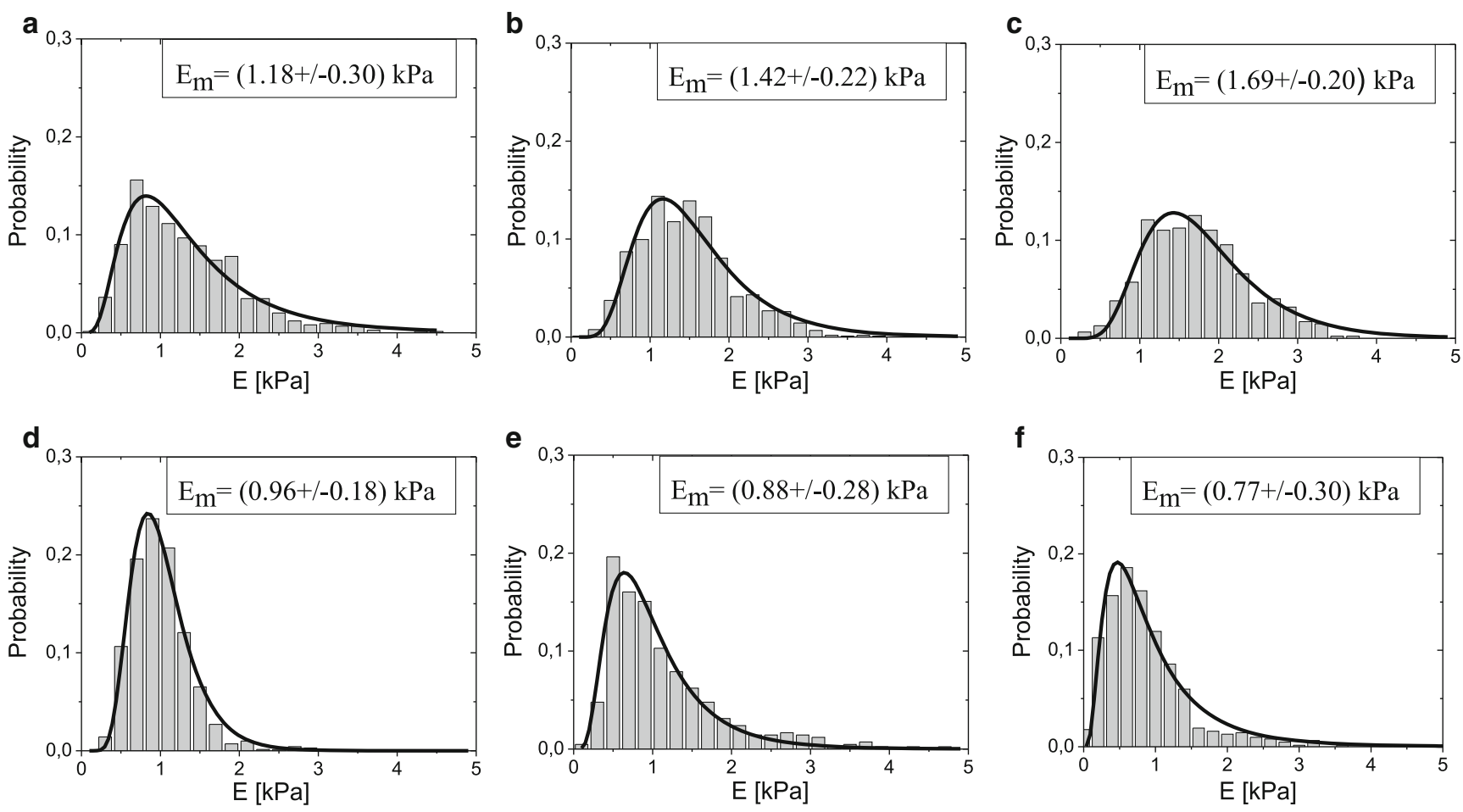

Fig. 2 Elasticity parameter $E$ distributions for control cells (a) and cells incubated with TNF- $\alpha$ for b 1 h, c 3 h, d 6 h, e 12 h, and f 24 h. Log-normal distribution fits (solid curves); resultant median and its fit inaccuracies are presented 
production after exposition to TNF- $\alpha$ in relation to the respective control samples were calculated.

\section{Results and discussion}

Morphology

Repetitive changes in cell morphology related to TNF$\alpha$ stimulation time are observed. Basing on the statistics from 26 to 28 cells for each incubation time, cell apical surface area, volume, shape, and height were analyzed in order to quantify the morphological response of HMEC to TNF- $\alpha$. Additionally, both AFM and fluorescent images brought information about cell distribution on the surface. For the control sample, cells mainly group in layered regions of tightly connected cells forming cobblestone-like pattern. For 1-h incubation with cytokine, the structure remains unchanged; however, many intercellular gaps could be observed (Fig. 6b), as also mentioned in [20]. Longer incubation time $(3 \mathrm{~h})$ showed diversity: Fragments of cobblestonelike pattern are still present, but numerous intercellular gaps dominate the structure. Cells exposed to TNF- $\alpha$ for $6 \mathrm{~h}$ and more tent to form islands, although for 12 and $24 \mathrm{~h}$, the cell distribution is far less ordered.

The large AFM scan size $(100 \times 100 \mu \mathrm{m})$ was used in order to visualize the whole cell together with lamellipodia. The image was plane-flattened and the cell height was measured. The cell apical part, considered

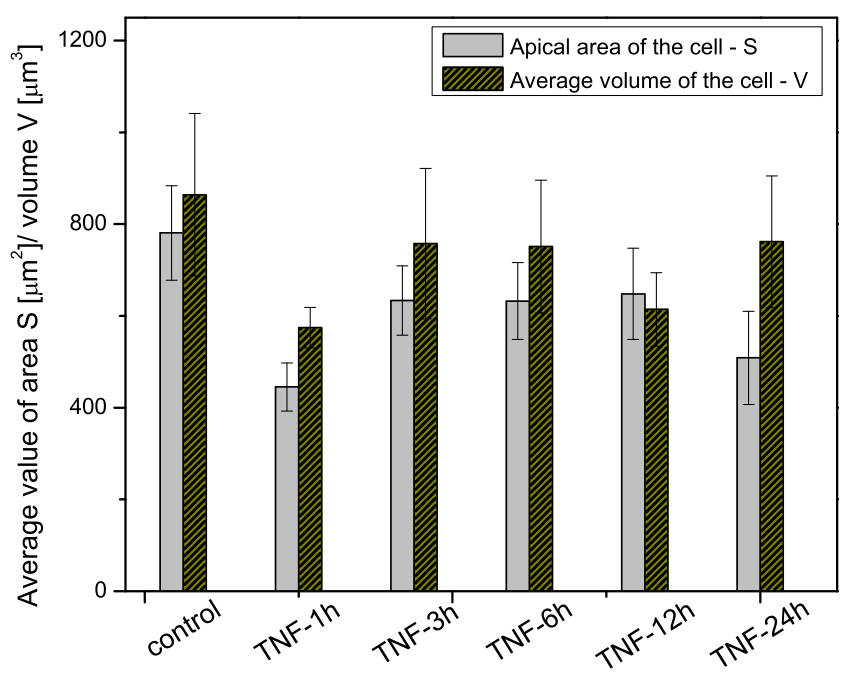

Fig. 3 Average apical cell surface area and volume for different periods of incubation with TNF- $\alpha$ based on AFM images analysis. The substantial change between the control and 1-h incubation, followed by further smaller variations are connected with cell cytoskeleton reorganization as top half of the cell based on the measured height, was analyzed to calculate volume and surface area. Values averaged for 26 to 28 cells are presented in Fig. 3. Apart from volume and surface area, the aspect ratio was calculated. It was taken as a ratio between the apical cell part length (as the longest chord of cell cross section at half of the height) and width (distance along the axis perpendicular to the previous chord). This parameter indicates the cell elongation. The increased value of this parameter followed by the drop in cell height is related to the cell elongation. On the other hand, the cell turning into spherical shape results in the decrease in aspect ratio and growth in height. Figure 4 presents averaged results of aspect ratio and height based on morphology measurements. Additionally, the topography of selected apical cell parts representative for given cytokine incubation period is shown in Fig. 5 (images $30 \times 30 \mu \mathrm{m})$.

It could be observed that TNF- $\alpha$ influenced all of the parameters used to characterize the cell morphology and the TNF- $\alpha$ response was dependent on the incubation time. For the control sample (Fig. 5a), which is not exposed to TNF- $\alpha$, spindle-shaped cells are dominant. The biggest difference in all parameters occurred for 1-h cytokine incubation. For 1-h incubation with TNF$\alpha$, cells tend to contract and take the shape closer to spherical (Fig. 5b), which is connected with about $30 \%$ reduction in aspect ratio and an increase in height followed by the drop in apical area and average volume. For the following 3- and 6-h incubation periods, both surface area and volume have risen in relation to $1 \mathrm{~h}$, while aspect ratio and height remained unchanged. Interestingly, for $12 \mathrm{~h}$, only an increase in height can be observed, while fluctuations of another parameters

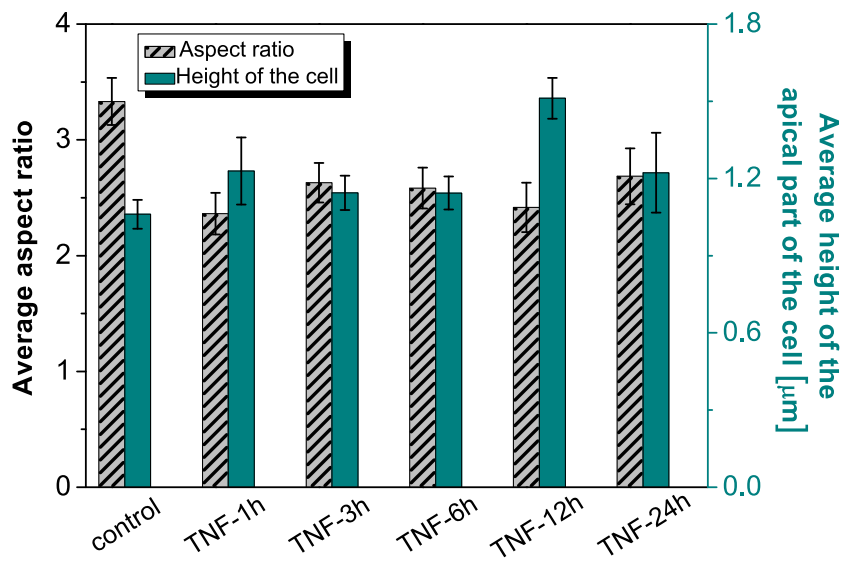

Fig. 4 The graph presents the aspect ratio, i.e., the proportion between the length and width of the apical part of the cell, which reflects the cell shape. Observed changes correspond to the modifications of apical surface area and volume 
Fig. 5 AFM images presenting $30 \times 30 \mu \mathrm{m}$ morphology scans of the HMEC incubated with TNF- $\alpha$. The spindle-shaped control cell (a) was not exposed to cytokine. b-f Representative cells stimulated with TNF- $\alpha$ for 1 , $3,6,12$, and $24 \mathrm{~h}$, respectively. Images revealed the change of cell shape: from spherical $(1 \mathrm{~h})$ to longitudinal for longer incubation periods a
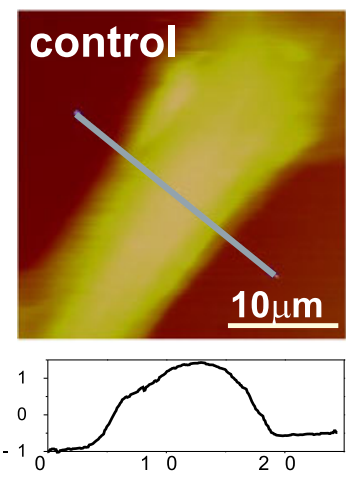

Distance $[\mu \mathrm{m}]$

d

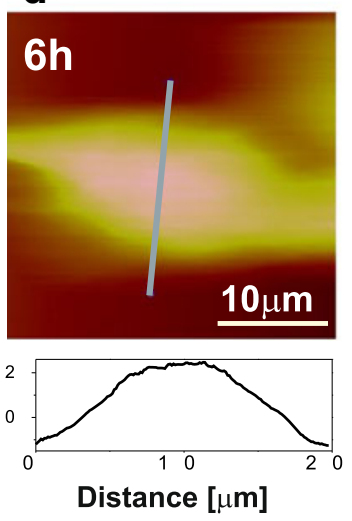

b
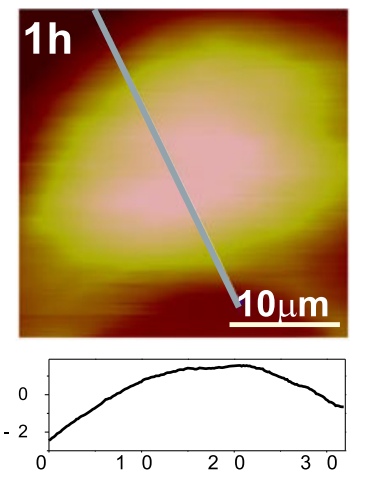

Distance $[\mu \mathrm{m}]$

e
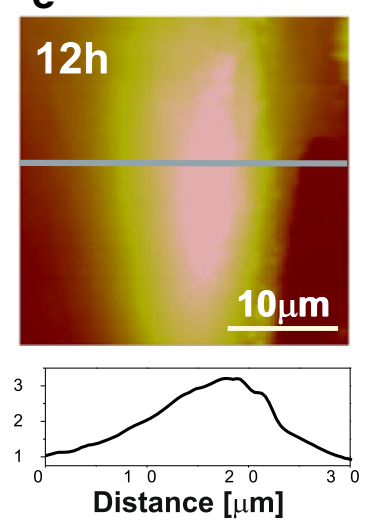

C
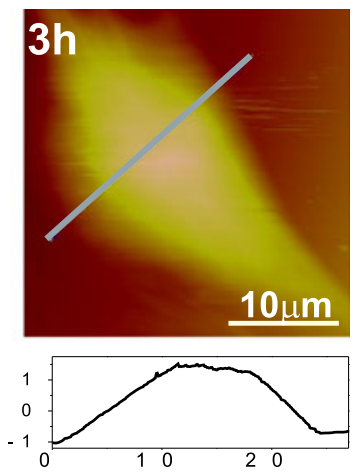

Distance $[\mu \mathrm{m}]$

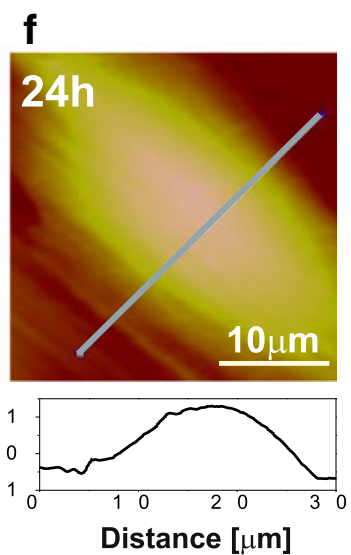

do not extend above statistical inaccuracy. This pattern of endothelium response might be connected to strong proinflammatory activation [3] and rapid depolymerization of F-actin ("Fluorescence-actin skeleton analysis" section). Surprisingly, incubation with TNF$\alpha$ for $24 \mathrm{~h}$ showed higher values of apical surface area and volume in relation to $12 \mathrm{~h}$, although the dispersion of those parameters between different cells was quite high.

Fluorescence—actin skeleton analysis

Figure 6 depicts the representative fluorescence images for different incubation periods with TNF- $\alpha$. Microfilaments consist of actin in two forms: Gactin (globular actin, monomeric subunits) and F-actin (filamentous actin). F-actin is a crucial part of cytoskeletal fibers, which determine the shape and elastic properties of the cell. Hence, cells were stained for Factin fibers (green) and nucleic acids (blue). It can be seen that $\mathrm{F}$-actin fibers undergo distinct modification under the influence of TNF- $\alpha$. For the control, quiescent endothelial cells, mainly thin fibers, are present going round the cell edges. The incubation with TNF- $\alpha$ for $1 \mathrm{~h}$ resulted in the creation of thin, parallel, and rather dense fibers structuring along main cell axis (arrow 1 in Fig. 6b) and round at cell edges (arrow 2) in a significant fraction of all cells. The observation can be explained by actin polymerization that leads to the formation of F-actin fibers [20]. Effects of continuing polymerization are visible for longer incubation $(3 \mathrm{~h})$ in Fig. 6c. The fibers which group along the cell main axis seem to form thicker bundles, as denoted with arrow 3 , while fibers going around cell edges are still present for the places where endothelial cells have cobblestone appearance. Figure $6 \mathrm{~d}$ shows diversification in F-actin location and structure for $6 \mathrm{~h} \mathrm{TNF}-\alpha$ stimulation. A fraction of cells include thick F-actin bundles (arrow 6); however, most of them seem to have the F-actin content decreased compared to the shorter incubation. Furthermore, shortened fibers of irregular orientation are observed (arrow 5), which is characteristic for the Factin depolymerization process [2]. The process seems to continue, as the significant intensification of the latter effect is observed for $12 \mathrm{~h}$ (arrow 7) and $24 \mathrm{~h}$ (arrow 8 ) incubation with cytokine (Fig. 6e), where numerous short, chaotically oriented fibers are visible in most of the cells. 


\section{a) control}

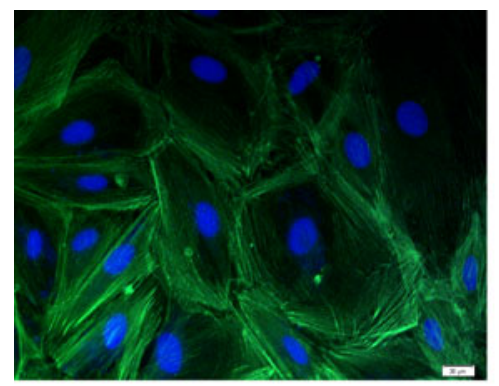

d) TNF- $\alpha 6 \mathrm{~h}$

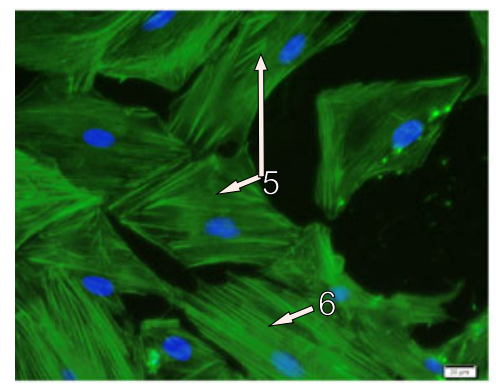

e) TNF- $\alpha 12 \mathrm{~h}$
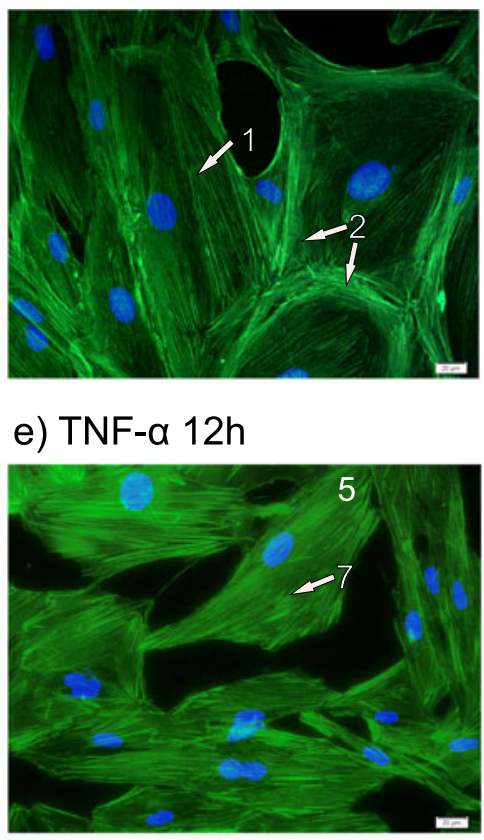

c) TNF- $\alpha 3 \mathrm{~h}$

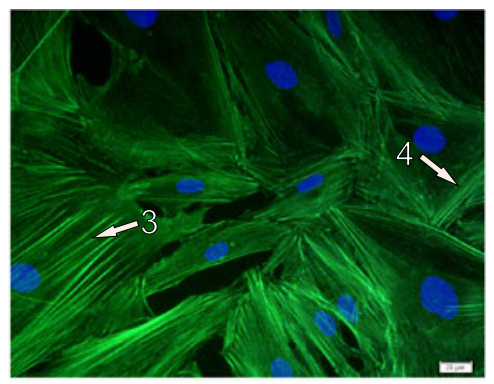

f) TNF- $\alpha 24 h$

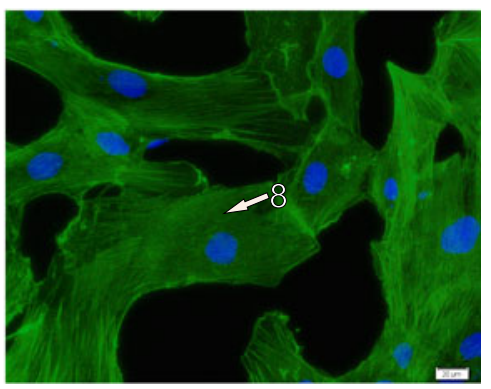

Fig. 6 a-f Fluorescence images showing the effect of TNF- $\alpha$ incubation on HMEC cells stained for F-actin fibers (green) and nucleic acids (blue). Visible scale bars-100 $\mu \mathrm{m}$. In the absence of cytokine, cells create brick-like pattern with actin filaments placed tangentially around the nucleus. Short incubation time

The elasticity changes in response to TNF- $\alpha$ in HMEC cells

Cumulative elasticity parameter histograms (Fig. 2) depict changes caused by stimulation with TNF- $\alpha$. Median is determined basing on log-normal distribution fit (Table 1). In order to compare the data, the relative change $\eta_{i}$ is calculated:

$\eta_{i}=\frac{\bar{E}_{i \mathrm{TNF}}-\bar{E}_{i \text { control }}}{\bar{E}_{i \text { control }}}$,

Table 1 Median of elasticity parameter determined by lognormal distribution fits to experimental data histograms for HMEC control and TNF- $\alpha$ treated cells

\begin{tabular}{|c|c|c|c|c|}
\hline \multirow[t]{2}{*}{$\begin{array}{l}\text { Incubation } \\
\text { period }\end{array}$} & \multicolumn{2}{|c|}{$\begin{array}{l}\text { Elasticity parameter } \\
\text { for cells with } \\
\text { TNF- } \alpha(\mathrm{kPa})\end{array}$} & \multicolumn{2}{|c|}{$\begin{array}{l}\text { Elasticity parameter } \\
\text { for control } \\
\text { samples }(\mathrm{kPa})\end{array}$} \\
\hline & Value & HWHM & Value & HWHM \\
\hline $1 \mathrm{~h}$ & 1.42 & 0.63 & 1.02 & 0.52 \\
\hline $3 \mathrm{~h}$ & 1.69 & 0.70 & 1.37 & 0.74 \\
\hline $6 \mathrm{~h}$ & 0.96 & 0.35 & 1.16 & 0.56 \\
\hline $12 \mathrm{~h}$ & 0.88 & 0.46 & 1.18 & 0.60 \\
\hline $24 \mathrm{~h}$ & 0.77 & 0.41 & 0.98 & 0.52 \\
\hline
\end{tabular}

Half of the full width at half maximum is noted next to the fitted distribution median brings the elevation of F-actin at cell edges (arrows 2 and 4), while parallel arrangement of fibers along cell main axis is also observed (arrows 1 and 3). Longer incubation time brings reorganization of the cytoskeleton, which manifests in shortening of parallel fiber groups (arrows 5, 7, and 8)

where $\bar{E}_{i \text { control }}$ and $\bar{E}_{i \mathrm{TNF}}$ are the medians of elasticity parameter $E$ for control cells and cells stimulated with TNF- $\alpha$ after $i \in\{1,3,6,12,24\}$ h of incubation (Fig. 7). Root mean square deviation value corresponds to inaccuracy of the log-normal distribution median fit (values marked at Fig. 2).

A two-stage response in cell elasticity is evoked by TNF- $\alpha$ stimulation. Concurrently, TNF- $\alpha$ stimulation results in the alteration of the proportion between $\mathrm{G}$ actin and F-actin.

A short incubation with cytokine $(1 \mathrm{~h})$ leads to polymerization of actin fibers which is located in the cytoplasm, and thus, F-actin becomes the dominant form. During polymerization of monomeric G-actin, cell contraction and stress fiber formation are observed [20]. Results of F-actin staining discussed in "Fluorescence-actin skeleton analysis" section have revealed the cytoskeleton reorganization induced by TNF- $\alpha$. Both the creation of numerous peripheral and parallel thin fibers inside the cell after $1 \mathrm{~h}$ of contact with TNF- $\alpha$ is observed. This may explain the significant increase in cell elasticity parameter. A simultaneous shrinkage in protrusions responsible for intercellular connections is observed. These effects are in agreement with the observed modification of cell shape (Figs. 3, 4, and 5b). Elasticity parameter after 


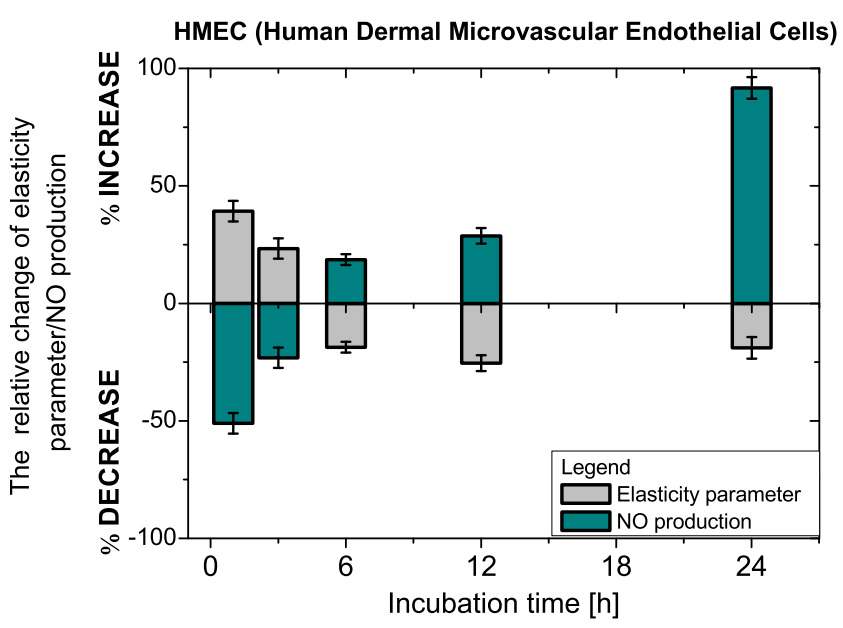

Fig. 7 HMEC elasticity and NO production changes in relation to control samples for different stimulation periods with TNF$\alpha$. The anti-correlation between this two parameters can be observed. Elasticity parameter reflects cell stiffness, i.e., the lower is the cell elasticity parameter, the softer is the cell

$3 \mathrm{~h}$ of incubation with TNF- $\alpha$ is still higher than for the unstimulated cells; however, it is reduced in relation to $1 \mathrm{~h}$. It may be connected to the changes of F-actin fiber configuration, as observed in fluorescent staining images (Fig. 6b, c) -for $3 \mathrm{~h}$, the fibers become thicker and less dense. Between 3 and $6 \mathrm{~h}$, the cells become softer than the unstimulated cells, which may reflect the beginning of the depolymerization process (as concluded from Fig. 6d). Longer incubation with TNF- $\alpha$ results in elasticity parameter smaller than for reference cells, which may evidence the continuing depolymerization of F-actin fibers.

Anticorrelation between elasticity and NO production

Nitric oxide production is related to the control value in an analogous way to elasticity. Results are presented on the same graph to visualize the relation between these two parameters (Fig. 7). NO production anticorrelates with elasticity parameter, i.e., the increase in one parameter is accompanied by the decrease of the other and conversely. This is in agreement with the observation made by Fels et al. that the "soft" cells release more nitric oxide than the "stiff" ones [8]. G-actin is known to increase the activity of eNOS (endothelium NO synthase) [18], which matches well the proposed relation between elasticity changes and actin cytoskeleton rearrangement.

To confirm the result, the NO production was measured using the same protocol for EA.hy926 endothelial cell line. Results are put together with elasticity
E.A.hy926 (Human Umbilical Vein Endothelial Cells)

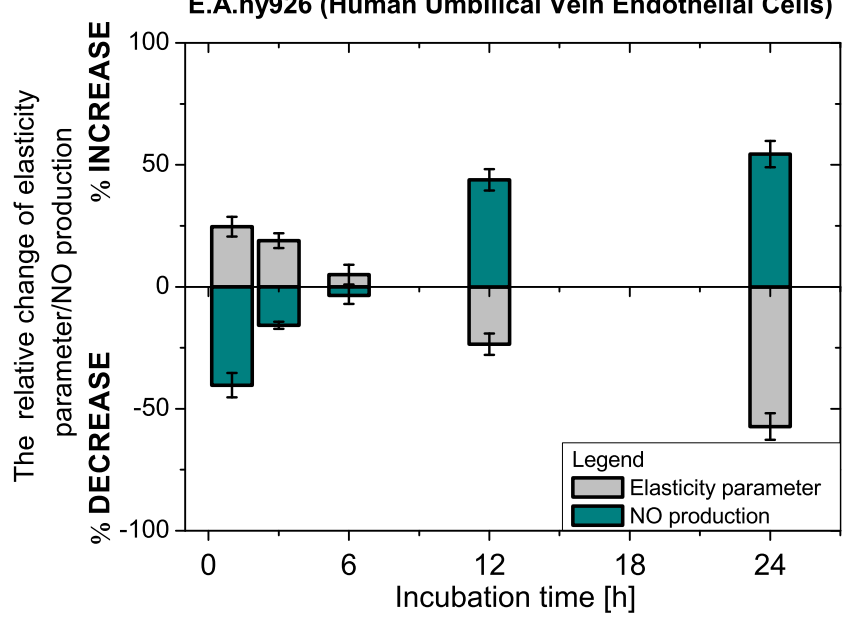

Fig. 8 EA.hy926 elasticity and NO production changes in relation to control samples for different stimulation periods with TNF- $\alpha$. The anticorrelation between those two parameters can be observed. Elasticity parameter reflects cell stiffness, i.e., the lower is the cell elasticity parameter, the softer is the cell

measurements performed earlier by our group (unpublished results) in Fig. 8. Despite slightly different absolute values specific for the cell line, the analogous tendency may be observed, which confirms the proposed interpretation. NO production is directly dependent on cell elasticity changes arising from actin cytoskeleton reorganization, as evidenced by Fels et al. [8]. The actin transition to its polymerized F-actin form leads to the increase in cell elasticity parameter accompanied with the reduction of NO production. The trend changes when cell elasticity parameter decreases. Then NO production intensifies, which is connected with G-actin domination.

\section{Conclusions}

In this paper, endothelial cell response to inflammatory cytokine TNF- $\alpha$ was characterized. The latter stimulates the immune system, having a significant influence on endothelial cells. It activates a cascade of characteristic inflammatory reactions, as production of interleukins, adhesion molecules, and other proinflammatory mediators. The impact of TNF- $\alpha$ on morphology and elasticity of endothelium and concomitant changes in NO production was examined in the context of cytoskeleton reorganization, which plays an important role in cellular processes and maintains cell shape and intercellular tight junctions. The proposed interpretation is in agreement with literature data, which relates the actin fiber configuration to $\mathrm{NO}$ production $[8$, 
18]. Actin and myosin fiber reorganization controlled by the Rho-dependent pathway directly influences the activity of eNOS enzyme and subsequently biological activity of endothelial NO that regulates permeability changes and other aspects of inflammatory response of the endothelium leading to endothelial dysfunction [5].

Endothelial cells exposed to TNF- $\alpha$ were characterized in respect to four different properties: morphology, elasticity, F-actin formation, and NO production estimated on the basis of nitrite concentration. Parameters evaluating those properties seem to be dependent on each other, as they are connected to actin filament reorganization. Noteworthy, the presented study compares TNF- $\alpha$ induced response in HMEC and EA.hy926 cell lines. Although these cells were derived from different vascular beds within the organism and they differ in size and culturing protocol, the overall tendency for changes in characterized parameters remains the same. TNF- $\alpha$ evokes two-stage inflammatory response of the endothelium characterized by an immediate increase in elasticity parameter, polymerization of F-actin, and decrease in NO production (1-3 h after TNF- $\alpha$ ) and subsequent progressive decrease in cells stiffness, Factin depolymerization, and increase in NO production (6-12 $\mathrm{h}$ after TNF- $\alpha$ ).

Undoubtedly, the results presented in this paper are in a good agreement with the proposed previously relationship between $\mathrm{NO}$ and cell elasticity presented in [8]. The increase in cell elasticity parameter connected with the contraction of the cell ( $1 \mathrm{~h}$ incubation) is linked to the increased formation of the polymerized fraction of actin. This is evidenced by fluorescent staining. At the same time, a reduction in NO production is observed. This behavior of the cell may be inferred as a first temporal reaction triggered by the initial inflammatory response and most likely can be linked to activation of endothelial reactive oxygen species production. The described endothelial proinflammatory activation that is of short duration is soon followed by a second phase during which cell undergoes functional transformation with the pronounced drop in cell elasticity parameter that makes the cells more susceptible to shear stress mediated by blood flow [8]. The latter is directly linked to the intensification of blood vessel permeability as well as complex proinflammatory and prothrombotic phenotypic changes of endothelium and may contribute to the perpetuation of the pro-inflammatory phenotype of the endothelium.

Acknowledgements Nitrite determination using Griess reagents was performed at the Department of Immunology, Jagiellonian University College of Medicine (Kraków, Poland) courtesy of Rafał Biedron. This work was supported by the European Union from the resources of the European Re- gional Development Fund under the Innovative Economy Program (grant coordinated by JCET-UJ, no. POIG.01.01.02-00069/09). Supplementary founding was provided by Polish Ministry of Science and Higher Education under the grant no. 3354/B/T02/2008/35.

Open Access This article is distributed under the terms of the Creative Commons Attribution Noncommercial License which permits any noncommercial use, distribution, and reproduction in any medium, provided the original author(s) and source are credited.

\section{References}

1. Biedroń R, Ciszek M, Tokarczyk M, Bobek M, Kurnyta M, Słominska E, Smoleński R, Marcinkiewicz J. (2008) 1-Methylnicotinamide and nicotinamide: two related antiinflammatory agents that differentially affect the functions of activated macrophages. Arch Immunol Ther Exp 56(2):127134

2. Boehmelt G (2000) Decreased UDP-GlcNAc levels abrogate proliferation control in EMeg32-deficient cells. EMBO J 19(19):5092-104.

3. Caprio M, Newfell BG, la Sala A, Baur W, Fabbri A, Rosano G, Mendelsohn ME, Jaffe IZ (2008) Functional mineralocorticoid receptors in human vascular endothelial cells regulate intercellular adhesion molecule-1 expression and promote leukocyte adhesion. Circ Res 102(11):1359-1367

4. Carl P, Schillers H (2008) Elasticity measurement of living cells with an atomic force microscope: data acquisition and processing. Pflügers Arch 457(2):551-559

5. Chang EH, Kyung-Sun, Woo CH, Lee H, Le NT, Thomas TN, Fujiwara K, Abe JI (2011) MK2 SUMOylation regulates actin filament remodeling and subsequent migration in endothelial cells by inhibiting MK2 kinase and HSP27 phosphorylation. Blood 117(8):2527-2537

6. Ding AH, Nathan CF, Stuehr DJ (1988) Release of reactive nitrogen intermediates and reactive oxygen. Comparison of activating cytokines and evidence for independent production. J Immunol 141(7):2407-2412

7. Edgell CJ, McDonald CC, Graham JB (1983) Permanent cell line expressing human factor VIII-related antigen established by hybridization. Proc Natl Acad Sci U S A 80:37343737

8. Fels J, Oberleithner H, Kusche-Vihrog K (2010) Ménage à trois: Aldosterone, sodium and nitric oxide in vascular endothelium. Biochim Biophys Acta 1802(12):1193-1202

9. Hertz H (1881) Über die berührung fester elastischer Körper, journal für die reine und angewandte mathematik. J Reine Angew Math 92:156-171

10. Lüscher T, Barton M (1997) Biology of endothelium. Clin Cardiol 20:II-3-II-10

11. Oberleithner $H$ (2007) Is the vascular endothelium under the control of aldosterone? Facts and hypothesis. Pflügers Archiv 454(2):187-93

12. Oberleithner H, Callies C, Kusche-Vihrog K, Schillers H, Shahin V, Riethmüller C, Macgregor G, de Wardener HE (2009) Potassium softens vascular endothelium and increases nitric oxide release. Proc Natl Acad Sci U S A 106(8): 2829-34

13. Oberleithner H, Schneider SW, Albermann L, Hillebrand U, Ludwig T, Riethmüller C, Shahin V, Schäfer C, Schillers H 
(2003) Endothelial cell swelling by aldosterone. J Membr Biol 196(3):163-72.

14. Oberleithner H, Riethmüller C, Schillers H, MacGregor G, de Wardener HE, Hausberg M (2007) Plasma sodium stiffens vascular endothelium and reduces nitric oxide release. Proc Natl Acad Sci U S A 104(41):16281-16282

15. Petrache I, Verin A, Crow M, Birukova A, Liu F, Garcia JGN (2011) Differential effect of MLC kinase in TNF- $\alpha$-induced endothelial cell apoptosis and barrier dysfunction factors differential effect of MLC kinase in TNF- $\alpha$-induced endothelial cell apoptosis and barrier dysfunction. Am J Physiol 280:L1168-L1178

16. Schäffer TE (2005) Calculation of thermal noise in an atomic force microscope with a finite optical spot size. Nanotechnology 16(6):664-670

17. Sneddon IN (1965) The relation between load and penetration in the axisymmetric Boussinesq problem for a punch of arbitrary profile. Int J Eng Sci 3(1):47-57
18. Su Y, Edwards B, Bubb S, Michael R, Block E (2003) Regulation of endothelial nitric oxide synthase by the actin cytoskeleton. Am J Physiol Cell Physiol 284(6):C1542C1549.

19. Szczepañski WK (2007) Endothelium-characteristics and functions. Pol Merkuriusz Lek XXIII(133):60-65

20. Wójciak-Stothard B, Entwistle A, Garg R, Ridley A (1998) Regulation of TNF-alpha-induced reorganization of the actin cytoskeleton and cell-cell junctions by Rho, Rac, and Cdc42 in human endothelial cells. J Cell Physiol 176(1):150-65

21. Zhang X, Wojcikiewicz EP, Moy VT (2006) Dynamic adhesion of $\mathrm{T}$ lymphocytes to endothelial cells revealed by atomic force microscopy. Exp Biol Med (Maywood, N.J.) 231(8):1306-1312

22. Zuk A, Targosz-Korecka M, Szymonski M (2011) Effect of selected drugs used in asthma treatment on morphology and elastic properties of red blood cells. Int $\mathrm{J}$ Nanomed 6 : 249-57. 